\title{
20. THE OPAQUE MINERALOGY OF BASALTS FROM DSDP LEG 26
}

\author{
J. M. Ade-Hall, Department of Geology, Dalhousie University, Halifax, Nova Scotia, Canada
}

\section{INTRODUCTION}

The opaque minerals of 25 basalt samples obtained on Leg 26 have been studied as a means of contributing to our knowledge of the petrology of the basalts and for better understanding their magnetic properties. As may be seen from another section of this report (Hyndman and Ade-Hall, this volume, Chapter 15) the study of the opaque mineralogy has also helped greatly in explaining the low electrical resistivity characterizing many of the basalts. Polished surfaces were prepared by treatment with successively finer abrasives, terminating with polishing for eight hours on a nylon cloth impregnated with $1-\mu$ diamond paste. The polished surfaces were examined using a Reichert Zeta Pan Pol ore microscope. A magnification of 1350 diameters with an oil immersion objective was used throughout this study.

\section{RESULTS}

The results of the examination of the polished surfaces are summarized in Table 1 . In this section I have chosen to discuss briefly the most interesting features resulting from the study.

Most submarine basalts described in the literature (Watkins and Paster, 1971; Irving et al., 1970) contain fine-diameter $(\leq 10 \mu)$ titanomagnetite grains of skeletal form (Plate 1, Figure 2) indicating rapid quenching of the basalt. These tiny magnetites are typically without any of the features of deuteric, high-temperature oxidation so commonly seen in subaerial basalts. Typical features of deuteric oxidation are ilmenite exsolution in octahedral planes in magnetite and the formation of titanohematite, rutile, and pseudobrookite from magnetite and ilmenite. Various degrees of deuteric oxidation can be recognized and a scale from Class 1 (no oxidation) to Class 6 (maximum oxidation) has been widely used in classifying basalts (Wilson et al., 1968). Thus, most samples studied to date are from quenched basalts, pillows, or flow tops, and contain Class 1 titanomagnetite. On the other hand, various degrees of low-temperature oxidation of magnetite have been recognized in submarine lavas, sometimes by optical and sometimes by magnetic methods (Ade-Hall et al., 1971). It has been widely recognized that the picture of the opaque mineralogy of submarine basalts, as described above, may well be biased as a result of most samples being from the accessible pillowed or otherwise chilled tops of flows. Now that greater penetration of Layer 2 is being achieved, a wider range of grain sizes, states of deuteric oxidation, and other features may be expected to be found. The results from the Leg 26 basalts bear out this expectation. Twenty of the $25(80 \%)$ basalt samples studied contain some magnetites in excess of $30 \mu$ in diameter while six $(24 \%)$ contain magnetites in excess of $100 \mu$ in diameter. Again, eight $(32 \%)$ contain magnetite in deuteric oxidation Class 2, 3, and 4. One sample in particular, Sample 254-36-3, $105 \mathrm{~cm}$, contains an opaque mineral facies typical of moderately to highly deuterically oxidized subaerial basalts (Table 1 and Plate 2, Figures 2, 3).

All the samples from Hole 251A, together with some samples from other sites, are wholly or nearly completely maghemitized. Samples $251 \mathrm{~A}-31-3,50 \mathrm{~cm}$; $251 \mathrm{~A}-31-4,48 \mathrm{~cm}$; and $251 \mathrm{~A}-31-5,105 \mathrm{~cm}$ are particularly interesting in that the maghemite has replaced the magnetite of large euhedral Class 2 grains while leaving the broad ilmenite lamellae apparently unaltered (Plate 2, Figure 1). This is an unusual opaque mineral facies, rarely reported for subaerial basalts and only once previously in a submarine basalt obtained on SIO dredgehaul FAN BD25 from the Mendocino Experiment (Ade-Hall, 1964).

A large fraction of the specimens is characterized by the occurrence of finely dispersed hematite or iron hydroxides, veins of hematite or pseudomorphs after ferromagnesian silicates containing a great deal of hematite. In one sample, Sample 254-36-3, $105 \mathrm{~cm}$, these features clearly formed during deuteric oxidation. In the other specimens, they probably owe their presence to breakdown of the primary oxides following various degrees of hydrothermal alteration. The irregular distribution of this type of alteration at Site 257, from which 11 samples were available, is of particular interest. It seems likely that alteration has proceeded along susceptible zones, possibly interflow zones while leaving the more massive interiors of flows relatively untouched.

\section{REFERENCES}

Ade-Hall, J. M., 1964. The magnetic properties of some submarine oceanic lavas: Roy. Astron. Soc. Geophys. J., v. 9 , p. 85 .

Ade-Hall, J. M., Palmer, H. C., and Hubbard, T. P., 1971. The magnetic and opaque petrological response of basalts to regional hydrothermal alteration: Roy Astron. Soc. Geophys. J., v. 24, p. 137.

Irving, E., Park, J. K., Haggerty, S. E., Aumento, F., and Loncarevic, B. D., 1970. Magnetism and opaque mineralogy of basalts from the Mid-Atlantic Ridge at $45^{\circ} \mathrm{N}$ : Nature, v. 228 , p. 974.

Watkins, N. D. and Paster, T. P., 1971. The magnetic properties of igneous rocks from the ocean floor: Roy. Soc. London Phil. Trans., Ser. A, v. 268, p. 507.

Wilson, R. L., Haggerty, S. E., and Watkins, N. D., 1968. Variation of palaeomagnetic stability and other parameters in a vertical traverse of a single Iceland lava: Roy. Astron. Soc. Geophys. J. v. 16, p. 79. 
TABLE 1

Opaque Mineralogy of Basement Rocks

(See also Plates 1 and 2)

\begin{tabular}{|c|c|}
\hline Sample & Description \\
\hline $250 \mathrm{~A}-26-2,140 \mathrm{~cm}$ & $\begin{array}{l}\text { Light-brown anhedral Class } 1 \text { magnetite in } 3-30 \mu \text { range. Some grains with spinel cores. Occasional ilmenite. } \\
\text { Ubiquitous fine sulphide. }\end{array}$ \\
\hline $250 \mathrm{~A}-26-6,58 \mathrm{~cm}$ & $\begin{array}{l}\text { Anhedral to skeletal brown to grayish-brown Class } 1 \text { magnetite in the } 4-40 \mu \text { range. Fairly abundant } \\
\text { elongate ilmenite. Ubiquitous minor pyrrhotite. }\end{array}$ \\
\hline $251 \mathrm{~A}-31-2,84 \mathrm{~cm}$ & $\begin{array}{l}\text { Gray-brown or silvery-gray maghemitized Class } 1 \text { magnetite. Grains have anhedral-skeletal form and range } \\
\text { up to } 40 \mu \text { linear dimension. }\end{array}$ \\
\hline $251 \mathrm{~A}-31-3,50 \mathrm{~cm}$ & $\begin{array}{l}\text { Anhedral-euhedral Class } 2 \text { magnetite of up to } 50 \mu \text { dimension. The magnetite partly or wholly replaced by } \\
\text { bluish maghemite. Large }(100 \mu) \text { orange-red pseudomorphs after olivine containing networks of hematite } \\
\text { veins. }\end{array}$ \\
\hline $251-31-4,48 \mathrm{~cm}$ & $\begin{array}{l}\text { Anhedral-euhedral Class } 2 \text { and occasional Class } 2 \text { magnetite of up to } 100 \mu \text { dimension. Magnetite almost } \\
\text { entirely replaced by off-white maghemite. Large dull-red areas in silicates (Plate 2, Figure 1). }\end{array}$ \\
\hline $251 \mathrm{~A}-31-5,105 \mathrm{~cm}$ & $\begin{array}{l}\text { Anhedral-euhedral Class } 2 \text { magnetite of up to } 200 \mu \text { dimension. Magnetite now wholly maghemitized. } \\
\text { Ilmenite lamellae apparently unaltered. Much brown staining and some hematite veins in the silicates. }\end{array}$ \\
\hline $253-58, \mathrm{CC}$ & $\begin{array}{l}\text { Anhedral to euhedral Class } 1 \text { or low Class } 2 \text { brown or pale-brown magnetite. Included ilmenite in most of } \\
\text { the larger grains. }\end{array}$ \\
\hline $254-31-1,111 \mathrm{~cm}$ & $\begin{array}{l}\text { Two size generations of opaques. Large euhedral to anhedral ilmenite, with occasional maghemitized Class } 1 \\
\text { magnetite, up to } 100 \mu \text { dimension. Also some grayish skeletal Class } 1 \text { magnetite, in the } 1-5 \mu \text { dimension } \\
\text { range, in interstitial areas. }\end{array}$ \\
\hline $254-35-1,107 \mathrm{~cm}$ & $\begin{array}{l}\text { Large grayish ilmenite and maghemitized Class } 1 \text { or low Class } 2 \text { magnetite up to } 200 \mu \text { dimension. Some } \\
\text { large (up to } 500 \mu \text { ) pseudomorphs consisting largely of hematite. Occasional fine hematite veins throughout } \\
\text { the sample. }\end{array}$ \\
\hline $254-36-3,105 \mathrm{~cm}$ & $\begin{array}{l}\text { Highly deuterically oxidized basalt. Rare anhedral Class } 3 \text { magnetite up to } 200 \mu \text { dimension (Plate 2, Figure 2) } \\
\text { together with relatively uncommon small Class } 4 \text { magnetites (Plate } 2 \text {, Figure } 3 \text { ). The main oxide phase is } \\
\text { partly deuterically oxidized euhedral ilmenite of up to } 100 \mu \text { dimension. Widespread hematite veining plus } \\
\text { finely distributed hematite. }\end{array}$ \\
\hline $256-9-12,2 \mathrm{~cm}$ & $\begin{array}{l}\text { Skeletal-anhedral brown Class } 1 \text { magnetite of up to } 50 \mu \text { dimension. Occasional suggestion of granulation. } \\
\text { Commonplace partial replacement of magnetite by golden yellow sphene. A wide red-brown vein contains } \\
\text { some massive hematite plus silvery hematized primary magnetites. }\end{array}$ \\
\hline $256-10-3,85 \mathrm{~cm}$ & $\begin{array}{l}\text { Brown and occasionally slightly gray-brown anhedral to skeletal Class } 1 \text { magnetite of up to } 60 \mu \text { dimension. } \\
\text { Ubiquitous minor pyrite. }\end{array}$ \\
\hline $256-11-1,15 \mathrm{~cm}$ & $\begin{array}{l}\text { Skeletal to anhedral grayish Class } 1 \text { magnetite of } 10-20 \mu \text { dimension. Occasional elongate grayish ilmenite. } \\
\text { Widespread minor pyrrhotite of up to } 50 \mu \text { dimension. Some globular masses of pyrrhotite have magnetite } \\
\text { fringes suggestive of reaction rims (Plate } 1 \text {, Figure 3). }\end{array}$ \\
\hline $256-11-3,15 \mathrm{~cm}$ & Brown Class 2 to 3 anhedral to skeletal magnetite of up to $60 \mu$ dimension. \\
\hline $257-11-2,74 \mathrm{~cm}$ & $\begin{array}{l}\text { Skeletal Class } 1 \text { magnetite plus some anhedral Classes } 1 \text { and } 2 \text { magnetite associated with separate ilmenite } \\
\text { grains. Magnetite up to } 50 \mu \text { dimension. Also some very fine interstitial magnetite. Ubiquitous minor pyrite. } \\
\text { Near a large vein the magnetite is of ten replaced by golden-yellow sphene. }\end{array}$ \\
\hline $257-11-3,130 \mathrm{~cm}$ & Chains of grayish skeletal Class 1 magnetite in an orange ground mass (Plate 2, Figure 2). \\
\hline $257-12-1,130 \mathrm{~cm}$ & $\begin{array}{l}\text { Three size generations of magnetite. The earliest in the } 10-50 \mu \text { range of pale brown to gray-brown anhedral } \\
\text { to euhedral Class } 1 \text { magnetite. Curved cracks and incipient granulation occur. Lilac-brown skeletal Class } 1 \\
\text { magnetite followed (Plate 1, Figure 1) often in red- or yellow-stained silicate areas. Finally, very fine } \\
\text { magnetite formed in interstitial areas. }\end{array}$ \\
\hline $257-12-3,85 \mathrm{~cm}$ & $\begin{array}{l}\text { Chains of lilac-brown skeletal Class } 1 \text { magnetite of up to } 10 \mu \text { dimension. Much orange and red staining in } \\
\text { the silicates plus hematite-replaced fragments of altered silicates. }\end{array}$ \\
\hline $257-13-3,15 \mathrm{~cm}$ & $\begin{array}{l}\text { Brown skeletal Class } 1 \text { magnetite of up to } 25 \mu \text { dimension together with an interstitial generation of fine } \\
\text { magnetite and some small sulphide. }\end{array}$ \\
\hline $257-14-2,95 \mathrm{~cm}$ & $\begin{array}{l}\text { Brown skeletal-anhedral-euhedral Class } 1 \text { magnetite of up to } 15 \mu \text { dimension, together with an interstitial } \\
\text { generation of very fine magnetite. Some large iron hydroxide (?) or hematized fragments of altered silicates } \\
\text { plus a frequent yellow or red staining of the silicates. }\end{array}$ \\
\hline $257-14-4,111 \mathrm{~cm}$ & $\begin{array}{l}\text { Brown skeletal-anhedral Class } 1 \text { magnetite of up to } 50 \mu \text { dimension plus abundant smaller sulphide (pyrite } \\
\text { and pyrrhotite) of up to } 15 \mu \text { dimension. }\end{array}$ \\
\hline $257-15-1,133 \mathrm{~cm}$ & $\begin{array}{l}\text { Brown skeletal-anhedral Class } 1 \text { magnetite of } 10-40 \mu \text { dimension plus a finer interstitial generation. Occa- } \\
\text { sional small pyrite. }\end{array}$ \\
\hline $257-16-2,145 \mathrm{~cm}$ & $\begin{array}{l}\text { Skeletal-anhedral brown Class } 1 \text { magnetite of up to } 30 \mu \text { dimension plus a finer interstitial generation. } \\
\text { Widespread small sulphide of up to } 8 \mu \text { dimension. }\end{array}$ \\
\hline $257-17-1,86 \mathrm{~cm}$ & $\begin{array}{l}\text { Brown skeletal Class } 1 \text { magnetite with small bluish areas of maghemite from } 30 \mu \text { down to the limit of visi- } \\
\text { bility at about } 0.5 \mu \text {. Some areas containing fine magnetite are red stained. Many orange-stained pseudo- } \\
\text { morphs after a ferromagnesian silicate. A broad vein cutting the sample contains much very fine or flaky } \\
\text { to massive hematite. }\end{array}$ \\
\hline $257-17-5,130 \mathrm{~cm}$ & $\begin{array}{l}\text { Two size generations of uniformly brown Class } 1 \text { anhedral to skeletal magnetite. The larger up to } 50 \mu \text {, the } \\
\text { smaller occur interstitially and ranges in size from } 1 \mu \text { downwards. Ubiquitous minor euhedral pyrite. }\end{array}$ \\
\hline
\end{tabular}



PLATE 1

Magnification $\times 1350$

Figure 1

Sample 257-16-2, $145 \mathrm{~cm}$.

Homogeneous brown skeletal Class 1 titanomagnetite (light gray) with peripheral small iron sulphides (white).

Figure 2

Homogeneous purple-brown skeletal Class 1 titanomagnetite (light gray) surrounded by redstained interstitial material possibly containing oxidized very fine magnetites.

Figure 3 Sample 256-11-1, $15 \mathrm{~cm}$.

Pyrrhotite globule (white) adjacent to large Class 1 titanomagnetite (medium gray). Note the peripheral disposition, possibly indicating a reaction origin, of small magnetites with respect to the pyrrhotite grain. 
PLATE 1
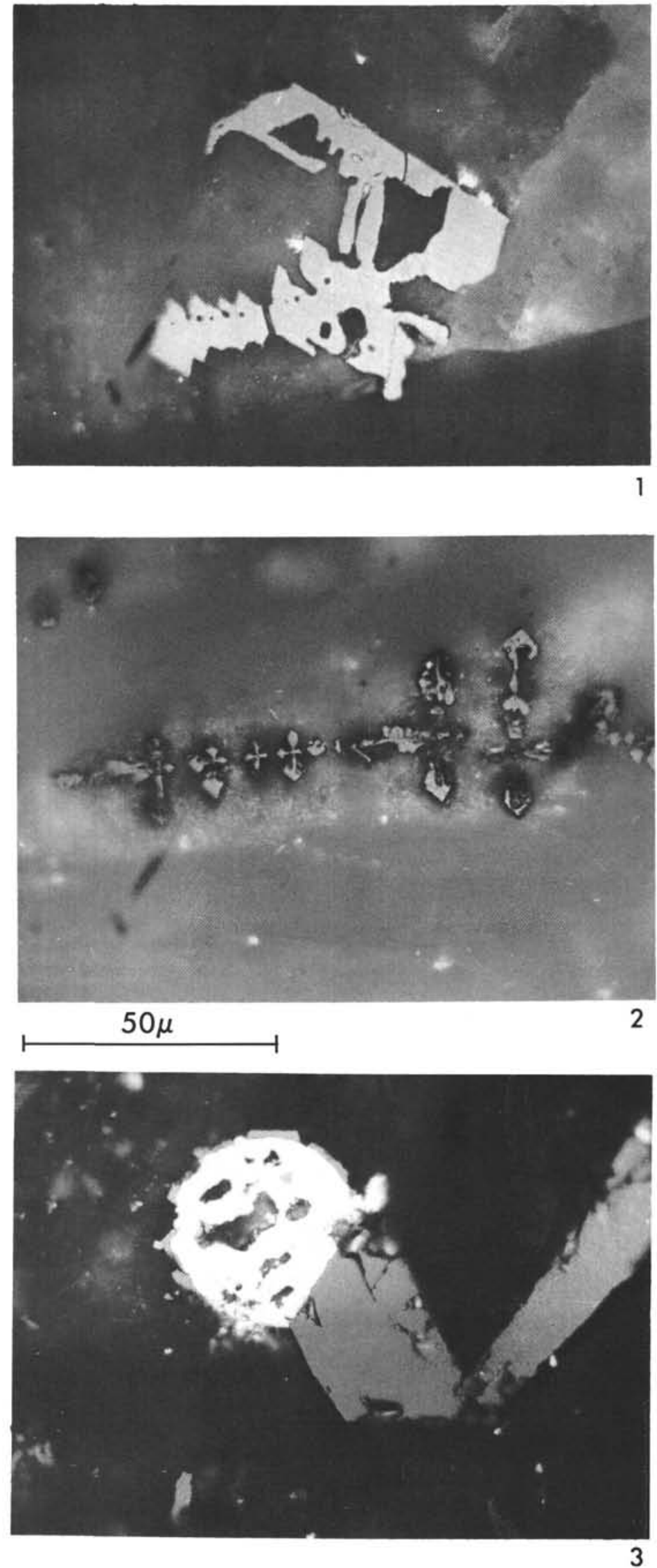
PLATE 2

Magnification $\times 1350$

Figure 1 Sample 251A-31-4, $48 \mathrm{~cm}$.

Large euhedral Class 2 titanomagnetite grain with the magnetite now almost entirely replaced by maghemite (off white to light gray). The ilmenite lamellae (medium gray) apparently unaltered.

Figure 2 Large anhedral Class 3 titanomagnetite grain consisting of abundant fine ilmenite lamellae (various shades of gray) exsolved in the octahedral planes of the original titanomagnetite grain. The remainder of the grain now consists of titanium deficient magnetite.

Figure 3 Euhedral Class 4 magnetite. White lamellae are relics of ilmenite lamellae now consisting of a fine aggregate of titanohematite and eutite. The gray base is titanium-deficient magnetite. 
PLATE 2
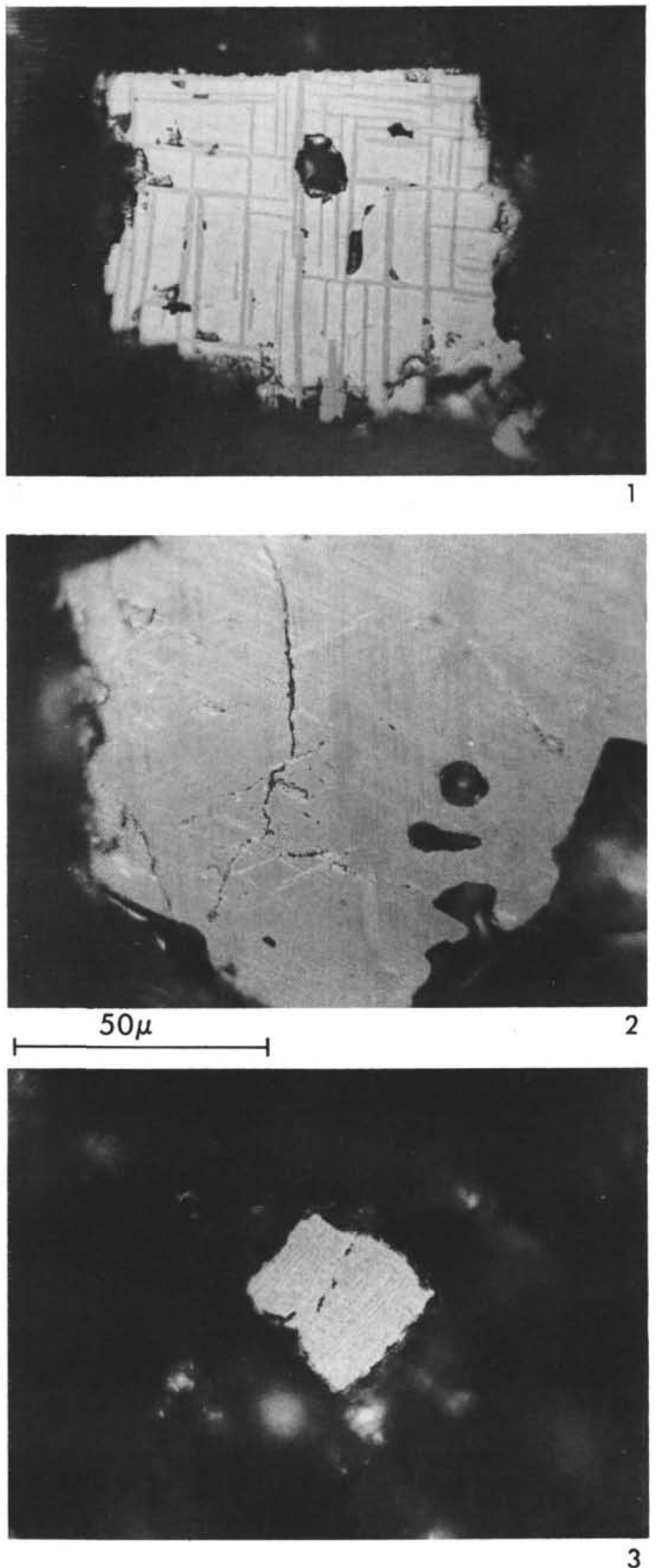